Vol 39 (2014) No 176 51-68

\title{
An Analysis of the Relationship between Academic Burnout and Classroom Assessment Environment
}

\author{
Mustafa İlhan ${ }^{1}$, Bayram Çetin ${ }^{2}$
}

\begin{abstract}
In this study, we aimed to examine the relationship between academic burnout and the classroom assessment environment. A causal-comparative model was employed in this study, which was carried out with 496 high school students in the provinces of Batman and Diyarbakir in Turkey in the spring of 2013-2014. The Maslach Burnout Inventory-Student Form (MBI-SF), which was developed by Schaufeli et al. (2002) and adapted into Turkish by Capri, Gunduz and Gokcakan (2011), was employed in the study to measure the students' levels of academic burnout. Then, in order to determine the students' perceptions of the classroom assessment environment, the Classroom Assessment Environment Scale (CAES), which was developed by the researchers of this study, was used. Cluster analysis was performed with the purpose of grouping students who have similar perceptions of the classroom assessment environment. This analysis produced three separate clusters. Then, analysis of variance was performed in order to determine whether the students' levels of academic burnout differed by the groups that had emerged out of the cluster analysis. The findings demonstrated that the students' levels of academic burnout differed significantly in accordance with their perceptions of the classroom assessment environment. Therefore, it could be suggested that the students' perceptions of the classroom assessment environment constitute a significant variable for the prediction of their levels of academic burnout.
\end{abstract}

Keywords

Academic burnout

Classroom assessment environment Cluster analysis

Article Info

Received: 06.05.2014

Accepted: 12.01.2014

Online Published: 12.16.2014

\section{Introduction}

\section{The Concept of Burnout}

Burnout, which is among the most important problems of modern times (Capulcuoglu \& Gunduz), was first theorized in the 1970s by Freudenberger. According to Freudenberger (1974), if the tasks that an individual is expected to fulfill exceed his/her energy and power, the individual feels ineffective, disappointed, and demotivated, and thus burnt out (Hotchkiss, 2008; Schwarz Cook, 2006). Although the notion of burnout was coined by Freudenberger (1974), most of what is known about the concept today is based on the theorization of Maslach and Jackson (1981) (Soliemanifar \& Shaabani, 2012). Maslach and Jackson (1981) define burnout as a three-dimensional structure that features

${ }^{1}$ Dicle University, Ziya Gökalp Faculty of Education, Primary Education Department, Turkey, mustafailhan21@gmail.com

${ }^{2}$ Gaziantep University, Gaziantep Faculty of Education, Department of Educational Sciences, Turkey, bcetin27@gmail.com 
emotional exhaustion, desensitization, and low sense of personal accomplishment. Emotional exhaustion constitutes the essential component of burnout (Maslach, Jackson \& Leiter, 1996) and refers to the individual's emotional jadedness (Lin \& Huang, 2010). Therefore, emotional exhaustion represents the inner aspect of burnout (Saglam Arı \& Cina Bal, 2008). The incongruity between the nature of a task and the characteristics of the person who is expected to carry out that task is the source of burnout. Individuals who experience emotional exhaustion feel that they lack the energy required to start a new work day or a new task. The second dimension of burnout is desensitization, which refers to the loss of idealist emotions about and interest in a given task (Maslach \& Goldberg, 1998), and the person exhibits negative, insensitive, and rigid attitudes towards individuals that he/she needs to interact with as part of the work (Kim, Lee, Kim, Choi \& Lee, 2014). Thus, it could be stated that desensitization represents the interpersonal aspect of burnout (Budak \& Surgevil, 2005). Decline in the feeling of personal accomplishment constitutes the third dimension of burnout. This dimension is characterized by the individual's tendency to perform negative self-evaluations (Skaalvik \& Skaalvik); he or she also experiences feelings of inefficacy when fulfilling the requirements of a task (Yang, 2004).

The notion of burnout was initially used for people who work in jobs that require serving individuals, such as nurses, doctors, teachers, lawyers, law enforcement officials, and psychologists (Maroco \& Campos, 2012; Maslach, Schaufeli \& Leiter, 2001). However, more recent research demonstrated that burnout is not a concept that is limited to jobs that necessitate close relationships with other people; in fact, it can be observed in all other professions (Leiter \& Schaufeli, 1996). Since essential activities pertaining to studying can also be seen as work, students might also experience burnout (Schaufeli, Martinez, Pinto, Salanova, \& Bakker, 2002). In other words, although students are not employees, from a psychological perspective, the practices that they are expected to perform (such as attending classes, participating in classroom activities, doing homework, and passing exams) are considered to be work (Lian \& Huang, 2010). Therefore, burnout can be experienced not only by employees, but also by students who are required to fulfill certain academic tasks (Parker \& SalmenaAro, 2011). Pines, Aronson and Kafry (1981), in their study in which they comparatively analyzed levels of burnout among university students, nurses, and advisors, determined that the scores that students got from the burnout scale ranged from the middle to the upper end of the scale. The authors interpreted this finding as being an indicator of the fact that students can also experience burnout. Burnout experienced by students is referred to as school-related burnout (Aypay, 2011; Kiuru, Aunola, Nurmi, Leskinen \& Salmela-Aro, 2008; Salmela-Aro \& Upadyaya, 2014) or academic burnout (Rostami, Abedi \& Schaufeli, 2012; Zhang, Klassen \& Wang, 2013). Throughout this study, we preferred to use the latter terminology.

\section{Academic Burnout}

Academic burnout refers to the chronic stress that students experience due to course load, exam anxiety, and other psychological factors (Shih, 2012; Yang, 2004). As in the original theory pertaining to the concept of burnout, academic burnout is also described in terms the dimensions of emotional exhaustion, desensitization, and a low sense of personal accomplishment (Schaufeli et al., 2002). Academic emotional exhaustion refers to chronic fatigue emerging from school-related work and anxiety about school, whereas academic desensitization can be defined as one's indifference to school-related activities, his or her distant attitude towards school, a loss of interest in academic activities, and seeing these activities as meaningless endeavors. A low sense of personal academic accomplishment, on the other hand, refers to the student's tendency to negatively assess his/her academic works, as well as his/her self-perception as an incompetent student (Salmela-Aro, Kiuru, Leskinen, \& Nurmi, 2009). 
Studies in the literature demonstrate that academic burnout is linked with many personal and contextual factors. Some of the personal factors that affect academic burnout are self-efficacy (Yang, 2004), fear of failure, suspicion about activities (Zhang, Gan \& Cham, 2007), gender (Balkis, Duru, Bulus \& Duru, 2011; Bas, 2011; Gunduz, Capri \& Gokbakan, 2012; Kalantarkousheh, Araqi, Moslem \& Mirzaee, 2013; Sever \& Aypay, 2011), exam anxiety (Capulcuoglu \& Gunduz, 2013), the ability to cope with stress (Capulcuoğlu \& Gunduz, 2013; Gan, Shang, Zhang, 2007), stress concerning academic expectations (Aypay, 2011), subjective well-being (Aypay \& Eryilmaz, 2011), life satisfaction (Rostami \& Abedil, 2012), achievement goal orientation (Shih, 2012), a tendency to procrastinate (Balkis, 2013), and locus of control (Kalantarkousheh et al., 2013). On the other hand, among the contextual factors that affect academic burnout are perceived social support (Jacobs \& Dodd, 2003; Kutsal \& Bilge, 2012), parents' attitudes (Capulcuoglu \& Gunduz, 2013), classroom environment (Adie \& Wakefield, 2011; Salmela-Aro, Kiuru, Pietikäinen \& Jokela, 2008; Valickienea, Zukauskienea \& Raiziene, 2011), learning materials presented to students in the classroom, academic guidance, and independent learning opportunities (Charkhabi, Abarghuei \& Hayati, 2013). Contextual factors that have a definitive impact on academic burnout, such as teacher social support, quality of learning conditions, academic guidance, and independent learning opportunities presented to students in the classroom, are among the components that constitute the classroom environment (Banks, 2012). Thus, it could be stated that the classroom environment and its components affect academic burnout. One of the most important components is the classroom assessment environment (Banks, 2012; Brookhart \& DeVoge, 1999).

\section{Classroom Assessment Environment}

Brookhart (1997) defines the classroom assessment environment as the perception of the classroom environment as created by the students via assessment objectives, assessment tasks, performance measures used in assessment, and feedback provided by the teacher (As quoted in: Alkharusi, Aldhafri, Alnabhani \& Alkalbani, 2013). In other words, students' perceptions of the classroom assessment practices constitute the classroom assessment environment (Brookhart \& DeVoge, 1999). Students' perceptions of the classroom assessment environment are examined under two headings: Learning-Oriented Assessment Environment (LOAE) and Performance-Oriented Assessment Environment (POAE) (Alkharusi, 2011). Those assessment environments in which assessment-related tasks are characterized by a moderate level of difficulty, assessment criteria are clearly defined, individual progress is prioritized over students' performances when compared to their peers (social comparisons), students are given feedback as to how to identify and eliminate deficiencies, learning-related efforts are more emphasized than the final outcome, mistakes are seen as natural components of the learning process, and students are given the chance to correct their mistakes ultimately create learning-oriented assessment perceptions among students. On the other hand, performance-oriented assessment perceptions are created among students by assessment environments where assessment-related tasks are difficult, exam grades are prioritized over learning, students' performance is prioritized over their effort, and social comparisons are taken as the criteria for success (Alkharusi, 2010). Students' levels of learning- and performance-oriented assessment perceptions affect their beliefs about their self-efficacy, their achievement goal orientations, and their academic performances (Alkharusi, 2008; Brookhart, Walsh \& Zientarski, 2006). For instance, while higher performance-oriented perceptions lead to lower beliefs of self-efficacy, higher learning-oriented perceptions lead to higher beliefs of self-efficacy (Alkharusi, 2009). 


\section{Relationship between Academic Burnout and the Classroom Assessment Environment}

Academic burnout plays an important role in many student behaviors, such as in the relationships that the students establish with teachers and other students in the learning process (Neumann, Finaly-Neuman \& Reichel, 1990). Therefore, endowing students with desired behaviors from a cognitive and sensorial perspective is closely linked with the prevention of academic burnout, which largely depends on the identification of factors that create and reinforce it (Grayson \& Alvarez, 2008). This fact has rendered the question: "What are the variables that contribute to the prediction of academic burnout?", which is one of the most essential problems to which answers are sought in research on student burnout (Charkhabi, Abarghuei \& Hayati, 2013). While addressing this question, Grayson and Alvarez (2008) distinguished variables that can be changed and controlled (such as teacher social support and school environment) from demographic variables that are impossible or difficult to alter (such as gender, family income, and parents' educational level). Thus, research that will examine the relationships between contextual factors (such as the school culture and classroom environment) and academic burnout are expected to contribute to the efforts aimed at preventing student burnout. Given the fact that academic burnout tends to be affected by the classroom environment (Adie \& Wakefield, 2011; Valickienea, Zukauskienea \& Saule, 2011), and that one of the main components that constitute the classroom environment is the assessment environment (Banks, 2012), it is thought that student burnout and the classroom assessment environment are interrelated structures. However, no studies were found in the literature that investigated the relationship between academic burnout and the classroom assessment environment. Since academic burnout brings about numerous negative characteristics such as depression (Capri \& Yedigoz Sonmez, 2013), lack of motivation, increased tendency to absenteeism, dropout (Meier \& Schmeck, 1985; Yang, 2004), and low academic achievement (Balkis, 2013; Balogun, Hoeberlein, Schneider \& Katz, 1996), identifying the assessment practices that work in favor of, as well as those that work against, academic burnout is of great importance - both for the students' health and for the functioning of the education system (Aypay \& Eryilmaz, 2011). By examining the relationship between academic burnout and the classroom assessment environment, it might be possible to determine what kind of an assessment environment should be established in order to decrease students' experience of academic burnout. In this respect, it is important to contribute to the relevant literature by conducting a study in which the relationship between academic burnout and the classroom assessment environment is investigated.

\section{Aim of the Research}

In this research, we aimed to examine the relationship between academic burnout and the classroom assessment environment. With this aim, it is hypothesized that students' levels of academic burnout will differ by their perceptions of the classroom assessment environment. 


\section{Method}

\section{Research Model}

The causal-comparative model was employed in this study. In studies that use this model, groups are formed based on the independent variable, and whether or not these groups differ with respect to the dependent variable is tested (Balci, 2009; Buyukozturk, Kilic Cakmak, Akgun, Karedeniz \& Demirel, 2010). Students' levels of academic burnout serve as the dependent variable, and the students' perceptions of the classroom assessment environment serve as the independent variable. Hence, we will obtain a research model that will be used to evaluate whether students' perceptions of the classroom assessment environment is a variable that affects their levels of academic burnout.

\section{Study Group}

The research was carried out in spring 2013-2014 with 496 high school students from the provinces of Batman and Diyarbakir. Of the participants, 259 (52.22\%) attended high school in Batman, whereas $237(47.78 \%)$ attended high school in Diyarbakir; $233(47 \%)$ were girls while 263 (53\%) were boys. Moreover, 149 (30.0\%) attended the 9th grade, $145(29.20 \%)$ attended the 10th grade, and $202(40.70 \%)$ attended the 11th grade. Various factors were influential in choosing our research group. Taking into consideration the accessibility principle, we conducted our research in Batman and Diyarbakir. Our study was conducted at four high schools; of them, two high schools were in Batman (one Anatolian high school and one Anatolian vocational high school), and two high schools were in Diyarbakir (Anatolian high schools). It needs to be emphasized that these high schools are owned by the Turkish government. Students who participated in the research were in grades 9 to 11 . Students in grade 12 were studying for university entrance exams; as such, they received rapport and did not attend school in March 2014. Since we collected data during that period, we could not communicate with these students. As a result, our research group did not include students in grade 12.

\section{Data Collection Instruments}

The Maslach Burnout Inventory-Student Form (MBI-SF) and Classroom Assessment Environment Scale (CAES) were employed as the data collection instruments in this study.

\section{The Maslach Burnout Inventory-Student Form (MBI-SF)}

The MBI-SF was employed in order to determine the students' levels of academic burnout. The MBI-SF was developed by Schaufeli et al. (2002) and adapted into Turkish by Capri, Gunduz and Gokcakan (2011). The scale contains three dimensions: emotional exhaustion, depersonalization, and personal accomplishment. The scale had 16 items in total. There were six items pertaining to personal accomplishment and five items pertaining to emotional exhaustion and desensitization. The original MBI-SF was graded on a 7-point Likert scale. In its Turkish version, however, a 5-point Likert-type grading scale was used. According to Seker and Gencdogan (2006), five point Likert-type grading at most make sense in Turkish. When more than five points is written, we see points that contain almost the same meaning. For that reason, the Turkish version of the scale is different than the original scale, and has only 5-point Likert-type grading. The construct validity of the Turkish version of the MBI-SF was examined through confirmatory factor analysis (CFA). Based on the CFA results, items 12 and 15 were removed since their $t$-values were not significant, and item 6 was also removed since it correlated with factors beyond its dimension. After removing these three items from the scale; the CFA was repeated and the following fit indexes were obtained: RMSEA=.080, $\chi^{2} / \mathrm{sd}=5.9, \mathrm{TLI}=.93$, $\mathrm{CFI}=.95, \mathrm{GFI}=.93$, AGFI $=.90$, and $\mathrm{SRMR}=.049$. A modification was applied since the fit indexes were not within acceptable limits. As part of this operation, the error variances between items 4-7 under emotional exhaustion, 2-5 under desensitization, and 8-11 under personal accomplishment were correlated. In the CFA that was repeated after the modifications, a structure that contained 13 items and three factors with adequate fit indexes (RMSEA, .049; $\chi^{2} / \mathrm{sd}=2.87$, TLI=.97, CFI=.98, GFI=.97, AGFI=.95, SRMR=.037) was obtained (see Table 1). The reliability coefficients for the measures of the Turkish version of the MBI-SF were calculated using Cronbach's alpha and the test-retest method. For the measures, the following Cronbach's alpha coefficients were obtained: emotional exhaustion (.76), desensitization (.82), and personal accomplishment (.61). On the other hand, the test-retest reliability 
coefficients of the measures were as follows: emotional exhaustion (.76), desensitization (.74), and personal accomplishment (.70). The Cronbach's alpha coefficients calculated in this study for the measures obtained from the emotional exhaustion, desensitization, and personal accomplishment subscales were $.65, .77$, and .56 , respectively. Measures with reliability coefficients greater than .70 are considered reliable (Buyukozturk, 2010). However, since Cronbach's alpha coefficients tend to rise as the number of items on the scale increases (Urbina, 2004), a reliability coefficient greater than .50 is considered adequate for the reliability of measures in scales that have a limited number of items (Nunnally, 1978; Raines-Eudy, 2000). Therefore, it could be stated that the reliability coefficients calculated for the measures obtained from the MBI-SF's sub-dimensions fall within acceptable limits. Table 1 highlights the MBI-SF's dimensions, a sample item for each dimension, as well as the Cronbach's alpha coefficients calculated for the measures obtained from these dimensions.

Table 1. Number of Items, Sample Items, and Cronbach's Alpha Coefficients for the Measures Obtained from the MBI-SF's Dimensions

\begin{tabular}{lclc}
\hline Dimensions & $\begin{array}{l}\text { Number } \\
\text { of Items }\end{array}$ & \multicolumn{1}{c}{ Sample Items } & $\begin{array}{c}\text { Cronbach's } \\
\text { Alpha }\end{array}$ \\
\hline Emotional Exhaustion & 5 & $\begin{array}{l}\text { Studying or attending a class is really a } \\
\text { burden for me }\end{array}$ & .65 \\
\hline Desensitization & 4 & $\begin{array}{l}\text { I am suspicious about the importance of my } \\
\text { courses }\end{array}$ & .77 \\
\hline Personal Accomplishment & 4 & $\begin{array}{l}\text { I can effectively resolve the problems that I } \\
\text { encounter in my studies }\end{array}$ & .56 \\
\hline
\end{tabular}

\section{Classroom Assessment Environment Scale (CAES)}

In order to measure the students' perceptions of the classroom assessment environment in the research, the CAES (which had been developed by the researchers of this study) was employed. The Classroom Assessment Environment Scale developed by Alkharusi $(2009,2011)$ was used when writing down the items that were to be included in the CAES. We emailed Alkharusi and obtained permission to use his scale. Then, some of the items on the scale developed by Alkharusi $(2009,2011)$ were translated into Turkish and added to the CAES item pool. For instance, the item, "In this class, the assignments and activities are related to students' everyday lives", was translated verbatim to Turkish. Yet, some items that exhibited cultural and linguistic differences were partly changed during translation, and they were then added to the CAES item pool. To establish an item pool that completely reflects the structure to be measured, we consulted two experts on scale item preparation. One of these experts studies measurement and evaluation, and the other expert studies curriculum and instruction. Both of them obtained their PhD in their field of study. Following their suggestions, the item "In this class, exam results intend to inform students about their academic development" was added to the scale. The CAES's item pool was produced based on the dimensions of LOAE and POAE. An item pool was formed with nine items that reflect LOAE and ten items that reflect POAE. Then, in order to ensure the CAES's content and face validity, opinions were obtained from three assessment and evaluation experts, as well as from two curriculum and instruction experts. Since defining the content (scope) related to a subject requires judgment, experts and developers of the assessment instrument should share definitions (Tavsancil, 2010). Especially in multidimensional instruments that consist of more than one subscale, experts should decide whether the items, which are written down to determine the different dimensions of the construct that is being measured, are relevant (or not) to the dimension that they are expected to fall under (DeVellis, 2003). Thus, the experts were asked to assess the scale based on the LOAE and POAE dimensions, which had been taken as the basis when developing the scale. Based on the experts' opinions, it was decided that no items needed to be removed from the LOAE. On the other hand, of the experts we consulted, three of them said that instead of the item, "It 
is hard to have good grades in the exams of this class", it would be better to use the item, "The exams of this class are hard for students", so as to evaluate the POAE. Following their suggestion, we eliminated this item from the scale. Subsequently, 18 items (nine reflecting LOAE and nine reflecting POAE) remained on the scale. The scale was administered to the students using a 5-point Likert-type grading scale, and responses ranged from "Strongly Agree (5)" $\rightarrow$ "Strongly Disagree (1)". For construct validity of the comments based on the measures obtained from CAES, exploratory factor analysis (EFA) and CFA were performed. The EFA yielded a construct with two factors and 18 items that explained $31.52 \%$ of the total variance. By considering the contents of the items that were aggregated under the factors, as well as the theoretical structure, the first factor was named LOAE whereas the second was named POAE. The LOAE consists of nine items that explain $20.93 \%$ of the total variance. Factor loads of the LOAE's items ranged between .33 to .63 . On the other hand, the POAE consisted of nine items, which contributed to $10.60 \%$ of the total explained variance. The factor loads of the POAE's items ranged from .33 to .69 . CFA was performed in order to check the EFA results and the measurement model that was theoretically constructed. The findings obtained from the CFA demonstrated that the fit indexes $\left(\chi^{2} / \mathrm{sd}=1.84, \mathrm{GFI}=.91, \mathrm{AGFI}=.88, \mathrm{CFI}=.96, \mathrm{NFI}=.91, \mathrm{NNFI}=95, \mathrm{IFI}=.96, \mathrm{RMSEA}=.056\right.$, $\mathrm{SRMR}=.056$, PNFI $=.79$ and PGFI $=.71$ ) were adequate. Given the fact that a minimum of $30 \%$ is taken as the criterion for the ratio of variance explained in EFA (Bayram, 2009; Buyukozturk, 2010), that the items' factor loads are above the lower limit of .30 (Costello \& Osborne, 2005; Pallant, 2005), and that the fit indexes obtained from the CFA fall within acceptable limits, it could be stated that construct validity of the measures obtained using CAES is ensured. The reliability of the measures obtained from the CAES was calculated via Cronbach's alpha, composite reliability, and the test-retest method. The Cronbach's alpha coefficients were calculated as .73 for measures obtained from both the LOAE and POAE. The composite reliability coefficients were found to be .75 and .76 for measures obtained from the LOAE and POAE subscales, respectively. On the other hand, the reliability coefficients obtained through the test-retest method were the same (.93) for the measures obtained from both subscales. Measures with reliability coefficients greater than .70 are considered reliable (Tezbasaran, 1997). Thus, the reliability coefficients obtained via Cronbach's alpha, composite reliability, and the test-retest methods can be regarded as evidence for the reliability of the measures. An item analysis was performed in order to determine the discriminatory power of the CAES's items and to assess the predictive power of the total score. As part of the item analysis, the adjusted item total correlation was examined and $27 \%$ sub-upper group comparisons were made. In the analysis, it was determined that adjusted item total correlations ranged between .32 and .52 in the LOAE, and .26 and .54 in the POAE, and that the $t$-values regarding the differences between the $27 \%$ sub and upper groups were significant for all items on the scale. Adjusted item total correlations above .30 and significant $t$-values obtained through the $27 \%$ sub-upper group comparisons are considered to exhibit an item's discriminatory ability (Erkus, 2012). Based on these criteria, it could be stated that all items on the CAES are discriminatory. Table 2 presents the CAES's dimensions, a sample item from each dimension, as well as the Cronbach's alpha, composite reliability, and test-retest reliability coefficients calculated for the measures obtained from these dimensions. 
Table 2. Number of Items, Sample Items, and Reliability Coefficients for Measures Obtained from the CAES's Dimensions

\begin{tabular}{|c|c|c|c|c|c|}
\hline Dimensions & $\begin{array}{l}\text { Number } \\
\text { of Items }\end{array}$ & Sample Items & $\begin{array}{c}\text { Cronbach's } \\
\text { Alpha }\end{array}$ & $\begin{array}{l}\text { Composite } \\
\text { Reliability }\end{array}$ & $\begin{array}{l}\text { Test-retest } \\
\text { Reliability }\end{array}$ \\
\hline LOAE & 9 & $\begin{array}{l}\text { Assessment practices performed } \\
\text { in this classroom enable students } \\
\text { to see their strengths and } \\
\text { weaknesses }\end{array}$ & .734 & .753 & .932 \\
\hline POAE & 9 & $\begin{array}{l}\text { In assessments in this classroom, } \\
\text { greater emphasis is placed on } \\
\text { students' exam grades than on } \\
\text { their efforts. }\end{array}$ & .730 & .761 & .927 \\
\hline
\end{tabular}

When interpreting the sub-dimensions of the LOAE and POAE, it was decided that the mean values between $1.00-1.80$ be interpreted as "Strongly Disagree", 1.81-2.60 as "Disagree", 2.61-3.40 as "Unsure", 3.41-4.20 as "Agree", and 4.21-5.00 as "Strongly Agree". Therefore, if the mean scores that the students received from the LOAE and POAE were between 1.00-1.80, it was interpreted that their perceptions of the dimension are very low. The other intervals and interpretations are as follows: 1.812.60 low, 2.61-3.40 medium, 3.41-4.20 high, and 4.21-5.00 very high.

\section{Procedure}

The research data were collected in spring 2013-2014. The scale was administered to the students in a classroom setting in the presence of the researcher. Prior to administering the data collection instruments, the students were given information about the purpose of the research. They were assured that the data to be collected would be used only for research purposes and that they would not be shared with any other person or institution. It was also made clear that participation in the study would be on a voluntary basis. In addition, the researcher made it clear to them that responding to the scale honestly would be of utmost importance for the collection of valid and reliable data. The first part of the instrument included items about the variables of gender and class in order to collect demographic data. There were two possible ways to match the MBI-SF and CAES responses of a given student: by administering both of the scales simultaneously, or by asking the students to provide their names for each of the scales. Since we thought that the latter might prevent them from providing honest responses, we used the former method. Most of the students finished filling out the instruments within 15-20 minutes.

\section{Data Analysis}

We conducted a causal-comparative study in which students' academic burnout was the dependent variable, and where their perceptions of the classroom assessment environment served as the independent variable. In causal-comparative research, data analysis involves two steps. The first step is to group the data according to the independent variable; the second step is to check whether there is a difference among groups in terms of their relationship to the dependent variable (Fraenkel \& Wallen, 2006). Therefore, in the data analysis process, cluster analysis was first performed in order to group those students who had similar perceptions of the classroom assessment environment. Cluster analysis is a multivariate statistical technique used for the purpose of dividing objects into similar (homogenous) groups with respect to the feature in question (Ozdamar, 2010; Romesburg, 2004). Thus, cluster analysis groups individuals together based on their similar responses to a certain variable (Aldenderfer \& Blashfield, 1984; Ucar, 2010). In this study, with the aim of grouping the students in terms of their perceptions of the classroom assessment environment, cluster analysis was performed on scores taken from the LOAE and POAE. In the analysis, the non-hierarchical cluster method of $k$-means was employed. Non-hierarchical cluster methods are preferred when the researcher has is aware of the number of clusters beforehand (Cokluk, Sekercioglu \& Buyukozturk, 2012). It was predicted in this research that the students' perceptions of the classroom assessment 
environment would fall under one of three clusters: $i$ ) high learning-oriented perception and low performance-oriented perception, ii) medium-level learning- and performance-oriented perception, and iii) low learning-oriented and high performance-oriented perception. Given the existence of a negative correlation between the LOAE and POAE, it was assumed that clusters with both low or both high learning- and performance-oriented perceptions would not emerge. Therefore, the number of clusters was determined as three.

Following the cluster analysis, we attempted to determine whether the students' academic burnout levels would differ with respect to their perceptions of the classroom assessment environment. To this end, one-way multivariate analysis of variance (one-way MANOVA) was performed in order to test whether the students' scores from the MBI-SF's sub-dimensions of emotional exhaustion, desensitization, and personal accomplishment would differ with respect to the groups that had emerged as a result of the cluster analysis. In order to do this, we first needed to test whether the assumptions regarding MANOVA are met or not, because MANOVA brings about numerous additional conditions (Akbulut, 2010), while at the same time providing the advantages of considering the relationships between dependent variables (Field, 2005) and controlling for a possible Type I error (Bray \& Maxwell, 1982; Stevens, 2009; Stangor, 2010). For this reason, before performing the MANOVA, we tested whether the data would meet the assumptions regarding the MANOVA. We found out that the following assumptions were met: univariate and multivariate normality, nonpresence of extreme values in the dataset, linearity, multilinear correlation, and singularity. However, the Box's M-test gave a significant result, which means that the assumption of homogeneity of matrices is violated. In such cases in which the MANOVA's assumptions are not met, applying an analysis of variance (ANOVA) for each variable in relation to the dependent variable set is suggested. On the other hand, applying an ANOVA for each variable instead of applying MANOVA increases the likelihood of obtaining significant results, which are in fact insignificant, and thus may lead to Type I errors during the course of measurement (Akbulut, 2010). Therefore, if such a procedure is followed, Bonferroni correction should be carried out in order to keep a potential Type I error under control (Hinton, 2005). According to the Bonferroni correction, the $P$-value should be controlled firmly (Akbulut, 2010). Thus, the normal $P$-value (generally, .05) should be divided into the number of ANOVA (the number of dependent variables) to be performed, and then the value obtained should be taken as the criterion for significance (Pallant, 2005). Since the dependent variable set had three variables (emotional exhaustion, desensitization, and personal accomplishment), .05 was divided into $3[.05 / 3=.016]$ and .016 was taken as the criterion for significance while interpreting the one-way ANOVA results. In case the ANOVA results would point to significant differences, the Scheffe test was performed in order to determine the source of difference. Also, effect size was calculated to determine the size of the difference. The effect size shows the size of the difference between means. For the effect size, there are various statistics such as Cohen's d, Cohen's f, and Eta square. Eta square is preferred because it shows the ratio of variance in the dependent variable, as explained by the independent variable(s), and because it is among the analysis outcomes that are provided by the SPSS software for certain statistics such as variance analysis (Pallant, 2005). According to Cohen (1988), the difference between means is low if the Eta square value is between .01 and .06; it is medium if the value is between .06 and .14, and it is high if the value is .14 or greater (Akbulut, 2010, Pallant, 2005). 


\section{Results}

This section presents the research findings. First, cluster analysis was performed on the students' CAES scores. Cluster analysis yielded three clusters, with $131(26.41 \%)$ students in the first, $163(32.86 \%)$ in the second, and $202(40.73 \%)$ in the third. For these three clusters, descriptive statistics regarding the LOAE and POAE are presented in Table 3.

Table 3. Descriptive Statistics regarding the LOAE and POAE for the Three Clusters that Emerged in the Cluster Analysis

\begin{tabular}{|c|c|c|c|c|c|c|c|c|}
\hline Clusters & $\mathbf{n}$ & Dimension & $\bar{X}$ & sd & Minimum & Maximum & Range & Interpretation \\
\hline \multirow{2}{*}{1} & \multirow{2}{*}{131} & LOAE & 2.23 & .46 & 1.00 & 3.1 & 2.11 & Low \\
\hline & & POAE & 4.00 & .45 & 2.89 & 5.00 & 2.11 & High \\
\hline \multirow{2}{*}{2} & \multirow{2}{*}{163} & LOAE & 3.68 & .38 & 2.78 & 4.78 & 2.00 & High \\
\hline & & POAE & 2.45 & .44 & 1.00 & 3.33 & 2.33 & Low \\
\hline \multirow{2}{*}{3} & \multirow{2}{*}{202} & LOAE & 2.98 & .40 & 1.89 & 3.89 & 2.00 & Medium \\
\hline & & POAE & 3.11 & .30 & 2.11 & 3.89 & 1.78 & Medium \\
\hline
\end{tabular}

Table 3 shows that the LOAE and POAE mean scores of cluster 1 students are 2.23 and 4.00, respectively. Based on the score intervals that were taken as reference when interpreting the CAES, it could be stated that cluster 1 students have low learning-oriented perceptions and high performanceoriented perceptions of the classroom assessment environment. The LOAE and POAE mean scores of cluster 2 students are 3.68 and 2.45, respectively. Based on the score intervals that were taken as a point of reference when interpreting the CAES, it could be stated that cluster 2 students have high learning-oriented perceptions and low performance-oriented perceptions of the classroom assessment environment. Finally, the LOAE and POAE mean scores of cluster 3 students are 2.98 and 3.11, respectively. Based on the score intervals that were taken as a point of reference when interpreting the CAES, it could be stated that cluster 2 students have both medium-level learning-oriented and performance-oriented perceptions of the classroom assessment environment. The LOAE and POAE mean scores of these three groups are also presented in Graph 1.

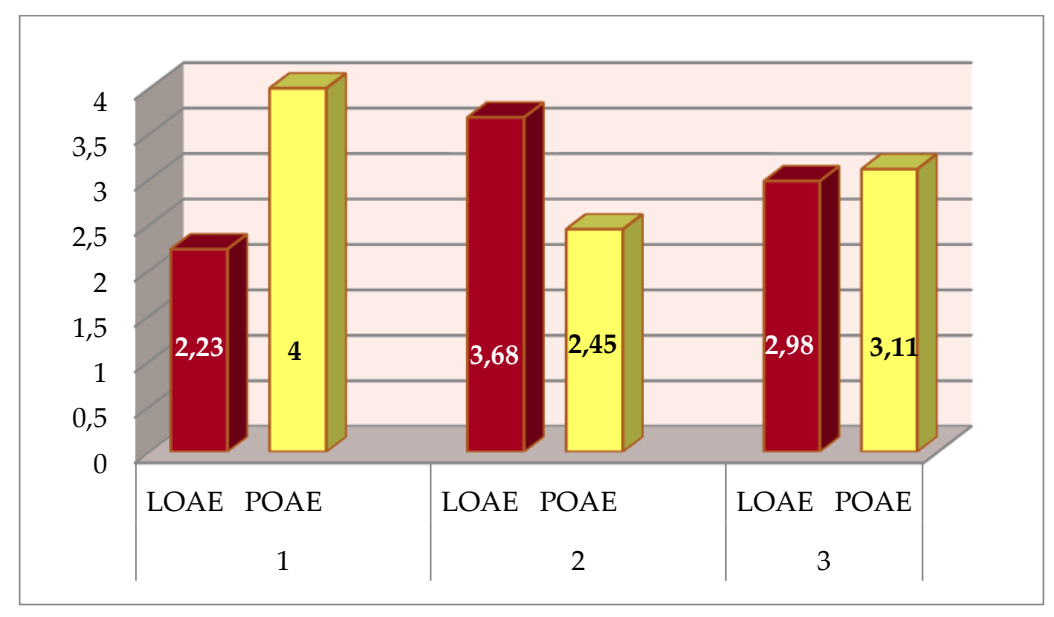

Graph 1. LOAE and POAE Mean Scores of the Clusters that Emerged in the Cluster Analysis 
In order to determine whether or not the differences between the LOAE and POAE mean scores received by students who fell under the different clusters were statistically significant, ANOVA was performed. ANOVA produced the result that the differences between both the students' LOAE $\left[\mathrm{F}_{(2,493)}=467.98, p<.01\right]$ and POAE $\left[\mathrm{F}_{(2,493)}=596.78, p<.01\right]$ mean scores were statistically significant. Following this finding, we also tested, via one-way ANOVA, whether the students' emotional exhaustion, desensitization, and personal accomplishment mean scores differed with respect to the clusters. Table 4 presents the relevant findings.

Table 4. ANOVA Results of the Emotional Exhaustion, Desensitization, and Personal Accomplishment Scores by Cluster

\begin{tabular}{|c|c|c|c|c|c|c|c|c|c|}
\hline $\begin{array}{c}\text { MBI-SF } \\
\text { Dimensions }\end{array}$ & Clusters & $\mathbf{n}$ & $\bar{X}$ & sd & df & $\mathbf{F}$ & $\mathbf{p}$ & $\begin{array}{c}\text { Eta } \\
\text { Squared }\end{array}$ & $\begin{array}{c}\text { Source of } \\
\text { Difference }\end{array}$ \\
\hline \multirow{3}{*}{$\begin{array}{l}\text { Emotional } \\
\text { Exhaustion }\end{array}$} & 1 & 131 & 3.99 & .82 & & & & & \multirow{9}{*}{$\begin{array}{l}\text { There exist } \\
\text { significant } \\
\text { differences for } \\
\text { all paired } \\
\text { comparisons }\end{array}$} \\
\hline & 2 & 163 & 2.89 & 1.14 & $2-493$ & 49.52 & .00 & .17 & \\
\hline & 3 & 202 & 3.36 & .81 & & & & & \\
\hline \multirow{3}{*}{ Desensitization } & 1 & 131 & 3.76 & 1.01 & \multirow{3}{*}{$2-493$} & \multirow{3}{*}{77.64} & \multirow{3}{*}{.00} & \multirow{3}{*}{.24} & \\
\hline & 2 & 163 & 2.35 & .90 & & & & & \\
\hline & 3 & 202 & 2.96 & .97 & & & & & \\
\hline \multirow{3}{*}{$\begin{array}{c}\text { Personal } \\
\text { Accomplishment }\end{array}$} & 1 & 131 & 3.15 & .88 & \multirow{3}{*}{$2-493$} & \multirow{3}{*}{25.51} & \multirow{3}{*}{.00} & \multirow{3}{*}{.09} & \\
\hline & 2 & 163 & 3.75 & .67 & & & & & \\
\hline & 3 & 202 & 3.41 & .66 & & & & & \\
\hline
\end{tabular}

Cluster 1: low LOAE, high POAE; Cluster 2: high LOAE, low POAE; Cluster 3: medium-level LOAE and POAE

Table 4 demonstrates that significant differences exist in all of the dimensions of academic burnout with respect to the clusters that emerged as a result of the cluster analysis. The highest mean score belongs to cluster 1 in the dimensions of emotional exhaustion and desensitization, which is followed by clusters 3 and 2, respectively. Based on the students' mean scores for the LOAE and POAE across all clusters, it could be stated that emotional exhaustion and desensitization increased as the performance-oriented perception of the classroom assessment environment also increased; conversely, emotional exhaustion and desensitization decreased as learning-oriented perception increased. The Eta squared values indicated that the students' perceptions of the classroom assessment environment have a $17 \%$ effect on their levels of academic emotional exhaustion, whereas they have a $24 \%$ effect upon the students' levels of desensitization. Based on the criteria used in interpreting the Eta square values, it could be stated that both of these effects are high.

On the other hand, on the dimension of personal accomplishment, cluster 2 had the highest mean score, followed by clusters 3 and 1, respectively. Based on the student's mean LOAE and POAE scores across all clusters, it could be stated that personal accomplishment increases as the learningoriented perception of the classroom assessment environment increased; conversely, it decreases as performance-oriented perception increases. The Eta squared value calculated for this dimension indicates that the students' perceptions of the classroom assessment environment have a 9\% (mediumlevel) effect on their levels of academic accomplishment. Graph 2 shows the students' mean scores for the sub-dimensions of the MTE-OF according to the groups in the clustering analysis. 


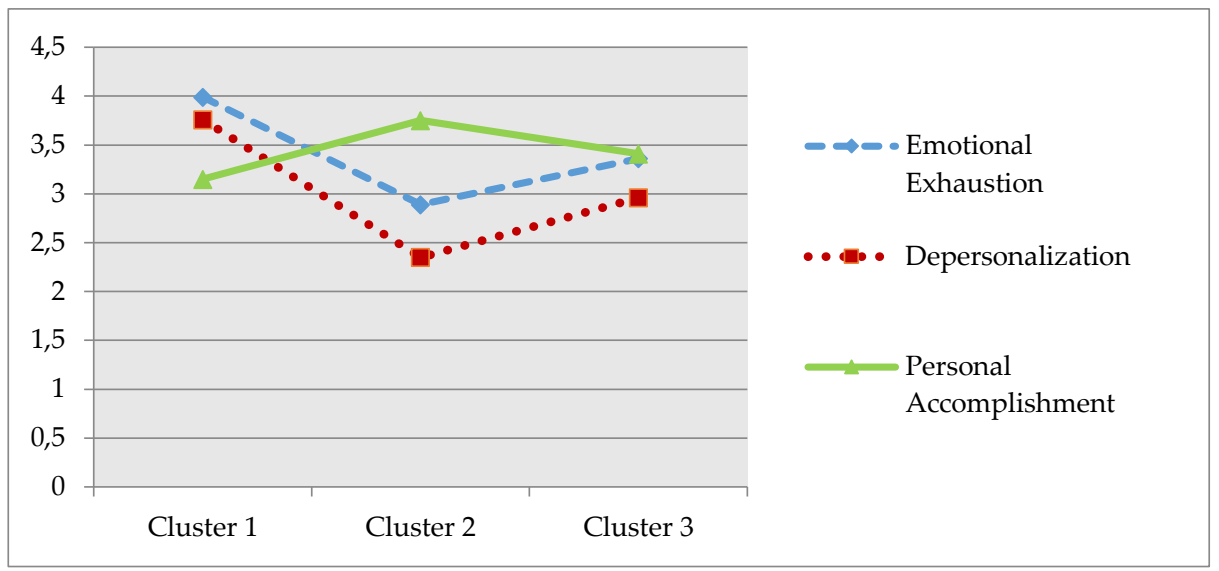

Graph 2. Students' Mean Scores for the Sub-Dimensions of the MTE-OF According to the Groups in the Clustering Analysis

\section{Discussion}

In this study, we aimed to examine the effect of students' perceptions of the classroom assessment environment on their levels of academic burnout. The findings indicated that students' levels of emotional exhaustion and desensitization decreased, and their levels of personal accomplishment increased as their learning-oriented perceptions of the classroom assessment environment increased. On the other hand, as their performance-oriented perceptions of the classroom assessment environment increased, their levels of emotional exhaustion and desensitization also increased, while their levels of personal accomplishment decreased. While the dimensions of emotional exhaustion and desensitization of the MBI-SF consist of expressions that support academic burnout, the dimension of personal accomplishment consists of expressions that do not support academic burnout. Therefore, it could be stated that there exists a negative correlation between students' learning-oriented perceptions of the classroom assessment environment and their levels of academic burnout, and a positive correlation between their performance-oriented perceptions and their levels of academic burnout. Thus, the research findings confirm the hypothesis of the study in that students' levels of academic burnout would differ with respect to their perceptions of the classroom assessment environment.

The findings of the current research are supported by the findings from other studies, in that students' perceptions of school and the classroom environment affect their cognitive and emotional processes (Kuperminc, Leadbeater \& Blatt, 2001). Many studies in the literature have determined that the perception of the classroom environment and academic burnout are interrelated structures. For instance, in the longitudinal study carried out by Salmela-Aro et al. (2008), it was found that a negative perception of school environment positively predicts academic burnout. Valickienea, Zukauskienea and Raiziene (2011) also found that the students' perceptions of the school and classroom environment have an impact upon academic burnout. Yet another study (which featured findings parallel to those of the current study) was conducted by Adie and Wakefield (2011), who designed it as a correlational study. They measured students' academic burnout using the MBI-SF and determined the students' perceptions of the classroom environment by employing the Learning Environment Scale. The researchers observed significant correlations between students' perceptions of the classroom environment and their levels of academic burnout. The studies listed above support our finding that there exists a significant correlation between academic burnout and students' perceptions of the classroom assessment environment. 


\section{Conclusion}

This study indicated that students' levels of perception of the classroom assessment environment serve as a variable that affects the students' levels of academic burnout. These results greatly contribute to the literature on academic burnout, as well as on the classroom assessment environment. The literature suggests that there are many individual and contextual factors that affect academic burnout; yet, the relationship between the classroom assessment environment and academic burnout was not questioned. This research explored this relationship, and contributes not only to the academic literature, but also to practice. The research results will serve as a guide for practices that intend to overcome academic burnout. The section "Implications for Practice" offers recommendations for using our research results in practice.

\section{Implications for Practice}

The statistically significant relationships found in this study between students' levels of academic burnout and their perceptions of the classroom assessment environment bring about several suggestions for practice. The findings that emotional exhaustion and desensitization increase and personal accomplishment decreases as students' performance-oriented perceptions of the classroom assessment environment increase indicate that a performance-oriented assessment environment triggers academic burnout. Therefore, in order to prevent academic burnout, practices that lead to the emergence of a performance-oriented assessment environment in a classroom should be avoided. In this respect, social comparisons between students should be avoided, tasks pertaining to assessment should not be too difficult for students, and students' efforts should be given priority over their performances.

As learning-oriented perceptions of the classroom assessment environment increase, personal accomplishment increases and emotional exhaustion and desensitization decrease. This can lead to the conclusion that learning-oriented assessment environments reduce academic burnout. Therefore, in order to prevent academic burnout, assessment practices that would contribute to the emergence of a learning-oriented assessment environment in a classroom setting should be given a degree of importance. Academic burnout can be prevented through the creation of a learning-oriented assessment environment by emphasizing efforts to learn rather than performing well, prioritizing students' individual progress over their comparative performances, giving them meaningful feedback about the assessment results, creating assessment tasks that are of medium-level difficulty, informing students about the assessment criteria, and seeing mistakes as integral components of the learning process. 


\section{Limitations of the Research and Implications for Future Studies}

Certain limitations exist in the current study, and it is believed that these limitations can be overcome by future studies. First, the relationship between the students' perceptions of the classroom assessment environment and academic burnout was investigated in this study by using a study group that consists of high school students. Thus, it is of great importance to test whether the significant correlations observed between the students' perceptions of the classroom assessment environment and academic burnout can be found in other samples, thus establishing generalizability of the findings. Second, it was found in this study that $17 \%$ of emotional exhaustion, $24 \%$ of desensitization, and $9 \%$ of personal accomplishment could be predicted by students' perceptions of the classroom assessment environment. This finding implies that $83 \%$ of emotional exhaustion, $76 \%$ of desensitization, and $91 \%$ of personal accomplishment are predicted by other variables. Other studies on the prediction of academic burnout demonstrate that among these variables are one's beliefs of his/her self-efficacy (Yang, 2004), perfectionism (Zhang, Gan \& Cham, 2007), subjective well-being (Aypay \& Eryilmaz, 2011), perceived social support (Kutsal \& Bilge, 2012), ability to cope with stress, exam anxiety, parental attitudes (Capulcuoglu \& Gunduz, 2013), achievement goal orientation (Shih, 2012), academic tendency to procrastinate (Balkis, 2013), and locus of control (Kalantarkousheh et al., 2013). Conducting a study in which all these variables are addressed together can help produce a model that predicts a much larger portion of the total variance regarding academic burnout. Moreover, the production of such a model can also guide efforts to reduce students' levels of academic burnout. Finally, it might be useful to carry out experimental research on the topic in order to obtain stronger evidence for the existence of a cause and effect relationship between perceptions of the classroom assessment environment and academic burnout. That a causal-comparative model was employed in the current, and that interpretations were made on the basis of findings obtained from other such studies renders our study more limited when compared to experimental studies (Balci, 2009, Fraenkel \& Wallen, 2006). Therefore, there is a need for experimental research on the subject in order to be able to draw the conclusion that students' levels of academic burnout differ with respect to their perceptions of the classroom assessment environment. 


\section{References}

Adie, J., \& Wakefield, C. (2011). Perceptions of the teaching environment, engagement and burnout among university students on a sports-related degree programme in the UK. Journal of Hospitality, Leisure, Sport \& Tourism Education, 10(2), 74-84.

Akbulut, Y. (2010). SPSS applications in social studies. İstanbul: İdeal Publishing.

Aldenderfer, M. S., \& Blashfield, R. K. (1984). Cluster analysis. Sage Publications, Inc.

Alkharusi, H. (2008) Effects of classroom assessment practices on students' achievement goals. Educational Assessment, 13(4), 243-266.

Alkharusi, H. (2009). Classroom assessment environment, self-efficacy, and mastery goal orientation: A causal model. Paper Presented at the $2^{\text {nd }}$ International Conference of Teaching and Learning (ICTL 2009), INTI University College, Malaysia.

Alkharusi, H. (2010). Teachers' assessment practices and students' perceptions of the classroom assessment environment. World Journal on Educational Technology, 2(1), 27-41.

Alkharusi, H. (2011). Development and data metric properties of a scale measuring students' perceptions of the classroom assessment environment. International Journal of Instruction, 4(1), 1308-1470.

Alkharusi, H., Aldhafri, S., Alnabhani, H., Alkalbani, M. (2013). Modeling the relationship between perceptions of assessment tasks and classroom assessment environment as a function of gender. Asia Pacific Education Researcher, 23(1), 93-104.

Aypay, A. (2011). Elementary school student burnout scale for grades 6-8: A study of validity and reliability. Educational Sciences: Theory \& Practice, 11(2), 520-527.

Aypay, A., \& Eryilmaz, A. (2011). Relationships of high school sdutents' subjective well-being and school burnout. International Online Journal of Educational Sciences, 3(1), 181-199.

Balci, A. (2009). Research methods, techniques and principles in social sciences. Ankara: Pegem Academy Publishing.

Balkis, M. (2013). The relationship between academic procrastination and students' burnout. Hacettepe University Journal of Education, 28(1), 68-78.

Balkis, M., Duru, E., Bulus, M., \& Duru, S. (2011). The prevalence of burnout among prospective teachers, it's relation with demographic variables and academic achievement. Pamukkale University Journal of Education, 29, 151-165.

Balogun, J. A., Hoeberlein-Miller, T. M., Schneider, E., \& Katz, J. S. (1996). Academic performance is not a viable determinant of physical therapy students' burnout. Percept Mot Skills, 83(1), 21-22.

Banks, S. R. (2012). Classroom assessment: Issues and practices. IL: Waveland Press Inc.

Bas, G. (2011). Teacher student control ideology and burnout: their correlation. Australian Journal of Teacher Education, 36(4), 84-94.

Bas, G. (2012). Burnout in elementary students: An evaluation with respect to some variables. Journal of Europan Education, 2(2), 31-46.

Bayram, N. (2009). Data analysis through SPSS in social sciences. Bursa: Ezgi Publishing.

Bray, J. H., \& Maxwell, S. E. (1982). Analyzing and interpreting significant MANOVAs. Review of Educational Research, 52(3), 340-367.

Brookhart, S. M., \& DeVoge, J. G. (1999) Testing a theory about the role of classroom assessment in student motivation and achievement. Applied Measurement in Education, 12(4), 409-425.

Brookhart, S. M., Walsh, J. M., \& Zientarski, W. A. (2006). The dynamics of motivation and effort for classroom assessments in middle school science and social studies. Applied Measurement in Education, 19(2), 151-184. 
Buyukozturk, S. (2010). A manual on data analysis in social sciences. Ankara: Pegem Academy Publishing.

Buyukozturk, S., Kilic Cakmak, E., Erkan Akgun, O., \& Karadeniz, S., \& Demirel, F. (2010). Scientific research methods. Ankara: Pegem Academy Publishing.

Budak, G., \& Surgevil, O. (2005). Exhaustion and an analysis of organizational factors affecting burnout on academic staff. Dokuz Eylul University Faculty of Economics and Administrative Sciences Journal, 20(2), 95-108.

Charkhabi, M., Abarghuei, M. A., \& Hayati, D. (2013). The association of academic burnout with selfefficacy and quality of learning experience among Iranian students. Springerplus, 2, 677.

Costello, A. B., \& Osborne, J. W. (2005). Best practices in exploratory factor analysis: Four recommendations for getting the most from your analysis. Practical Assessment Research $\mathcal{E}$ Evaluation, 10(7), 1-9.

Capri, B., Gunduz, B., \& Gokcakan, Z. (2011). Turkish adaptation of Maslach Burnout InventoryStudent Scale (MBI-SS). Çukurova University Faculty of Education Journal, 1(40), 134-147.

Capri, B., \& Yedigöz Sonmez, G. (2013). Investigation of burnout scores of high school students according to sociodemographic variables, psychological symptoms and attachment styles. International Journal of Human Sciences, 10(2), 195-218.

Capulcuoglu, U., \& Gunduz, B. (2013). Coping with stress, test anxiety, academic self-efficacy and parental attitudes in predicting student burnout. Journal of Educational Sciences Research, 3(1), 201218.

Cokluk, O., Sekercioglu, G., \& Buyukozturk, S. (2012). Multivariate statistics for the social sciences: SPSS and LISREL applications. Ankara: Pegem Academy Publishing.

Erkus, A. (2012). Measurement and scale development in psychology. Ankara: Pegem Academy Publishing.

Field, A. (2009). Discovering statics using SPSS. London: SAGE Publications Ltd.

Frankel, J. R., \& Wallen, N. E. (2006). How to Design and Evaluate Research in Education. New York: McGraw-Hill.

Gan, Y., Shang, J., \& Zhang, Y. (2007). Coping flexibility and locus of control as predictors of burnout among chinese college students. Social Behavior and Personality, 35(8), 1087-1098.

Grayson, J. L., \& Alvarez, H. K. (2008). School climate factors relating to teacher burnout: A mediator model. Teaching and Teacher Education, 24(5), 1349-1363.

Gunduz, B., Capri, B., \& Gokcakan, Z. (2012). Examining of the burnout level of university students. Journal of Ziya Gokalp Faculty of Education, 19, 38-55.

Hinton, P. R. (2005). Statistics explained. London: Routledge.

Hotchkiss, N. F. (2008). Predictors of reactivation and gender differences at a physician health program by age, marital status, primary presenting problem, referral source, and referral status. Dissertation Abstracts International: Section B: The Sciences and Engineering, 2-B, 1369.

Jacobs, S., \& Dodd, D. (2003). Student burnout as a function of personality, social support, and workload. Journal of College Student Development, 44(3), 291-303.

Kalantarkousheh, M. S., Araqi, V., Moslem, Z., \& Mirzaee, F. O. (2013). Locus of control and academic burnout among Allameh Tabataba'i University students. International Journal of Physical and Social Sciences, 3(12), 309-321.

Kim, B., Lee, M., Kim, K., Choi, H., \& Lee, S. M. (2014). Longitudinal analysis of academic burnout in Korean middle school students. Stress Health, Advance online publication. Doi: 10.1002/smi.2553.

Kiuru, N., Aunola, K., Nurmi, J. E., Leskinen, E., \& Salmela-Aro, K. (2008). Peer group influence and selection in adolescents' school burnout: A longitudinal study. Merrill-Palmer Quarterly, 54(1), 2355. 
Kuperminc, G. P., Leadbeater, B. J., \& Blatt, S. J. (2001). School social climate and individual differences in vulnerability to psychopathology among middle school students. Journal of School Psychology, 39(2), 141-159.

Kutsal, D., \& Bilge, F. (2012). Study on the burnout and social support levels of high school students. Education and Science, 37(164), 283-297.

Leiter, M. P., \& Schaufeli, W. B. (1996) Consistency of the burnout construct across occupations. Anxiety, Stress \& Coping: An International Journal, 9(3), 229-243.

Lian, S. H., \& Huang, Y. C. (2010). Life stress and academic burnout. Active Learning in Higher Education, 20(10), 1-14.

Maroco, J., \& Campos, J. A. (2012). Defining the student burnout construct: A structural analysis from three burnout inventories. Psychological Reports: Human Resources \& Marketing, 111(3), 814-830.

Maslach, C., \& Goldberg, J. (1998). Prevention of burnout: New perspectives. Applied and Preventive Psychology, 7(1), 63-74.

Maslach, C., Jackson, S. E., \& Leiter, M. P. (1996). Maslach burnout inventory manual. Palo Alto, CA: Consulting Psychologists Press.

Maslach, C., Schaufeli, W. B., \& Leiter, M. P. (2001). Job burnout. Annual Review of Psychology, 52(1), 397-442.

Meier, S. F., \& Schmeck, R. R. (1985). The burned-out college student: A descriptive profile. Journal of College Student Personal, 26(1), 63-9.

Neumann, Y., Finaly-Neumann, E., \& Reichel, A. (1990). Determinants and consequences of students' burnout in universities. Journal of Higher Education, 61(1), 20-31.

Nunnally, J. C. (1978). Psychometric theory. New York: McGraw-Hill.

Ozdamar, K. (2010). Statistical data analysis via package programs 2 (Multivariate analysis). Eskisehir: Kaan Publishing.

Pallant, J. (2005). SPSS survival manual: A step by step guide to data analysis using SPSS for windows. Australia: Australian Copyright.

Parker, P. D., \& Salmena-Aro, K. (2011). Developmental processes in school burnout: A comparison of major developmental models. Learning and Individual Differences, 21(2), 244-248.

Pines, A., Aronson, E., \& Kafry, D. (1981). Burnout: from tedium to personal growth. New York: Free Press.

Raines-Eudy, R. (2000). Using structural equation modeling to test for differential reliability and validity: An empirical demonstration. Structural equation modeling: A Multidisciplinary Journal, $7(1), 124-141$.

Romesburg, H. C. (2004). Cluster analysis for researchers. North Carolina: Lulu Press.

Rostami Z., \& Abedi, M. R. (2012). Dose academic burnout predicts life satisfaction or life satisfaction is predictor of academic burnout? Interdisciplinary Journal of Contemporary Research in Business, 3(12), 668-674.

Rostami, Z., Abedi, M. R., \& Schaufeli, W. B. (2012). Dose interest predicts academic burnout? Interdisciplinary Journal of Contemporary Research in Business, 3(9), 877-895.

Sağlam Arı, G., \& Çına Bal, E. (2008). The concept of burnout: Its importance for individuals and organizations. Management and Economics, 15(1), 131-148.

Salmela-Aro, K., Kiuru, N., Leskinen, E., \& Nurmi, J. E. (2009). School-burnout inventory (SBI): Reliability and validity. European Journal of Psychological Assessment, 25(1), 48-57.

Salmela-Aro, K., Kiuru, N., Pietikäinen, M., \& Jokela, J. (2008). Does school matter? The role of school context in adolescents' school-related burnout. European Psychologist, 13(1), 12-23.

Salmela-Aro, K., \& Upadyaya, K. (2014). School burnout and engagement in the context of demandsresources model. British Journal of Educational Psychology, 84(1), 137-151. 
Schaufeli, W. B., Martinez, I. B., Pinto, A. M., Salanova, M., \& Bakker, A. B. (2002). Burnout and engagement in university students: A cross-national study. Journal of Cross-Cultural Psychology, 33(5), 464-481.

Schwarz Cook, S. L. (2006). Explaining burnout: A mixed method investigation of information technology workers. Unpublished Doctoral Dissertation, Capella University, Minneapolis, ABD.

Seker, H., \& Gencdogan, B. (2006). Development of measurement tools in psychology and education. Ankara: Nobel Publishing.

Sever, M., \& Aypay, A. (2011, October). An examination of school burnout in secondary school students in terms of some variables. Paper presented at the XI. National Congress of Psychological Counseling and Guidance, Izmir.

Shih, S. S. (2012) An Examination of academic burnout versus work engagement among Taiwanese adolescents. The Journal of Educational Research, 105(4), 286-298.

Skaalvik, E. M., \& Skaalvik, S. (2009). Does school context matter? Relations with teacher burnout and job satisfaction. Teaching and Teacher Education, 25(3), 518-524.

Soliemanifar, O., \& Shaabani, F. (2012). The relationship between of personality traits and academic burnout in postgraduate students. Journal of Life Science and Biomedicine, 3(1), 60-63.

Stangor, C. (2010). Research methods for the behavioral sciences. Wadsworth.

Stevens, J. P. (2009). Applied multivariate statistics for the social sciences. New York: Routledge.

Tezbasaran, A. (1997). Guide to develop Likert type scales. Ankara: Turkish Psychological Association.

Ucar, N. (2010). Cluster analysis. In S. Kalayci, (Eds.), Multivariate statistical techniques through SPSS (pp. 234-255). Ankara: Asil Yayın Publishing.

Urbina, S. (2004). Essentials of psychological testing. New Jersey: John Wiley \& Sons. Inc.

Valickienea, R. P., Zukauskienea, R., \& Raiziene, S. (2011). The role of attachment to school and open classroom climate for discussion on adolescents' school-related burnout. Procedia Social and Behavioral Sciences, 15, 637-641.

Yang, H. J. (2004). Factors affecting student burnout and academic achievement in multiple enrollment programs in Taiwan's technical-vocational colleges. International Journal of Educational Development, 24(3), 283-301.

Zhang, Y., Gan, Y., \& Cham, H. (2007). Perfectionism, Academic burnout and engagement among Chinese college students: A structural equation modeling analysis. Personality and Individual Differences, 43(6), 1529-1540.

Zhang, X., Klassen, R. M., \& Wang, Y. (2013). Academic burnout and motivation of Chinese secondary students. International Journal of Social Science and Humanity, 3(2), 134-138. 